\title{
SCHEME CAPTIONS
}

Scheme 1. The chemical structures of Teflon $\mathrm{AF}^{\circledR}, \mathrm{Cytop}^{\circledR}$, and Hyflon $\mathrm{AD}^{\circledR}$.

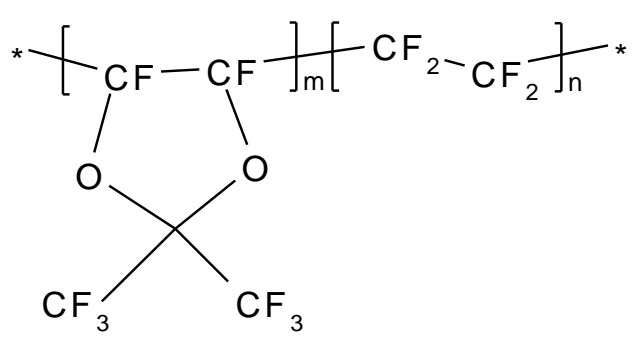

Teflon AF

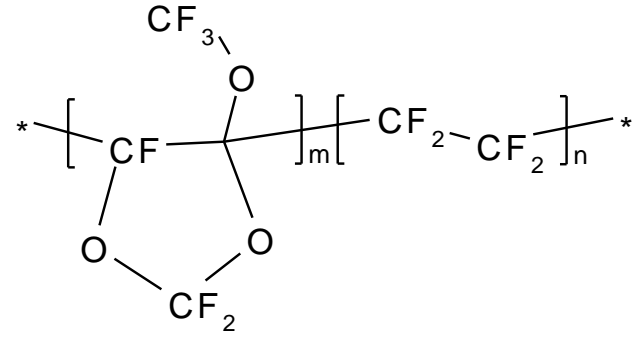

Hyflon AD

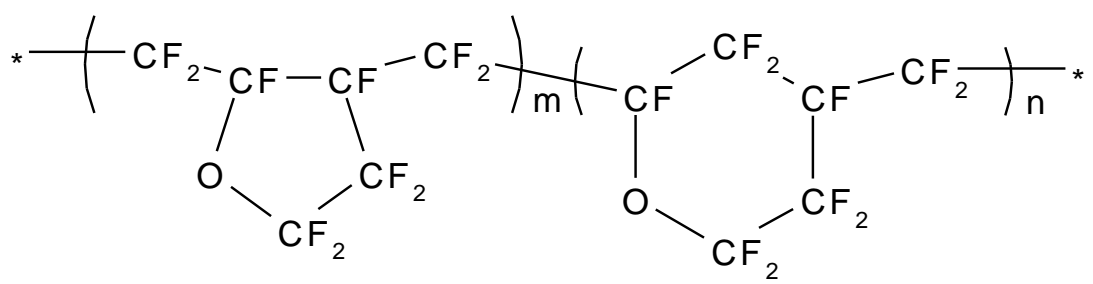

Cytop 
Scheme 2. Chemical structures of substituted perfluoro-2-methylene-1,3-dioxolane derivatives.

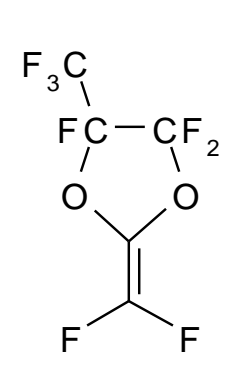

A

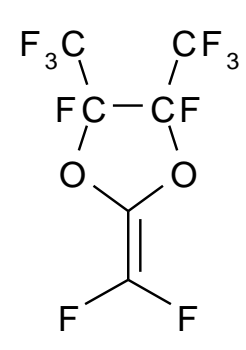

B

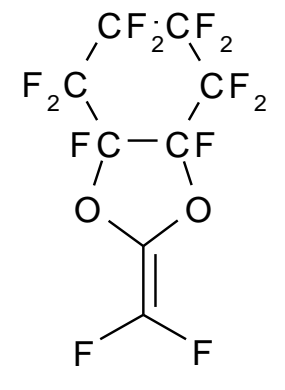

C

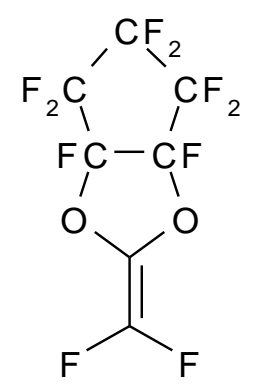

D 
Scheme 3. Synthetic route for perfluoro-3-methylene-2,4-dioxabicyclo[3,3,0] octane (monomer D).
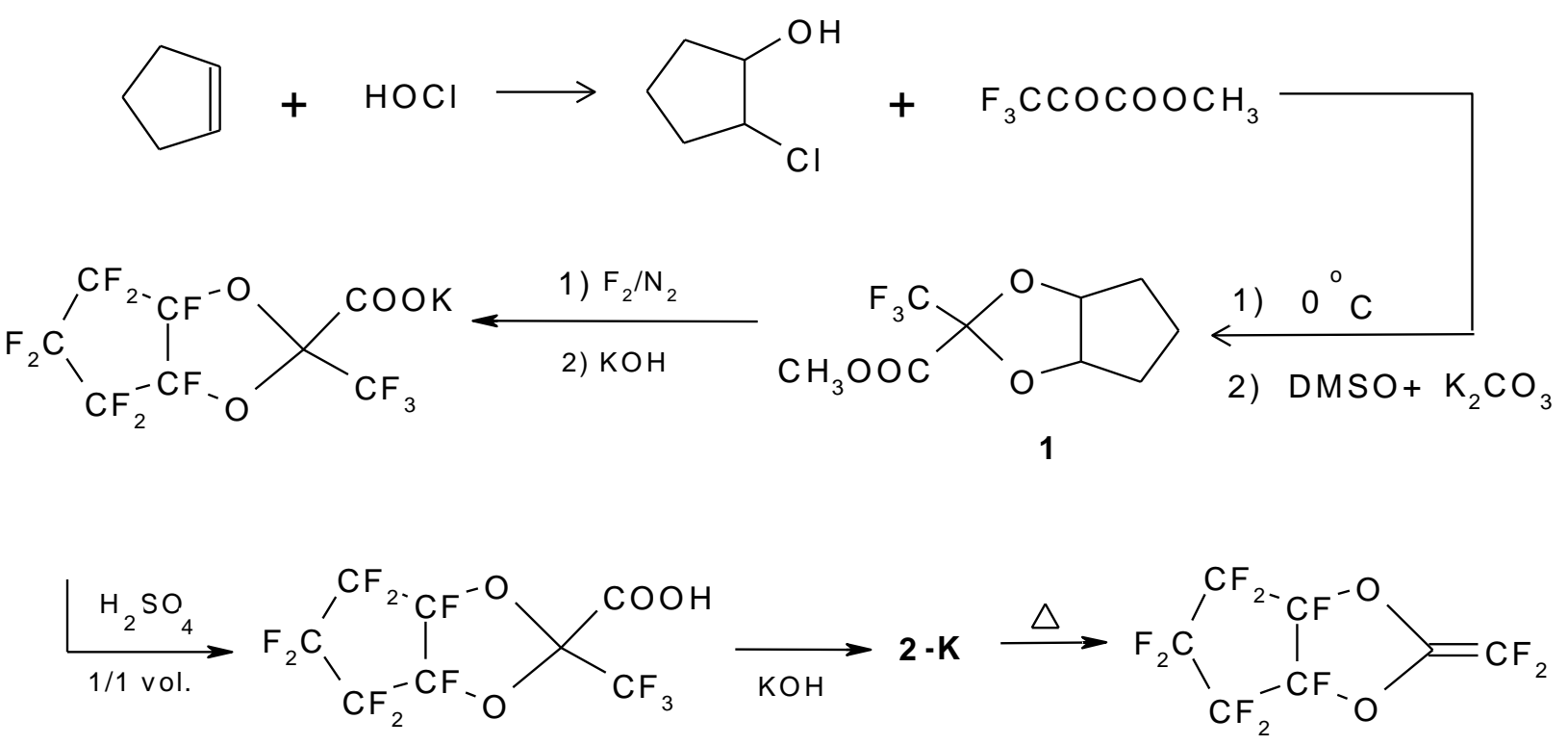
Scheme 4. Structure of copolymers based on perfluoro-3-methylene-2,4-dioxabicyclo[3,3,0] octane (monomer D) with fluorovinyl monomers.

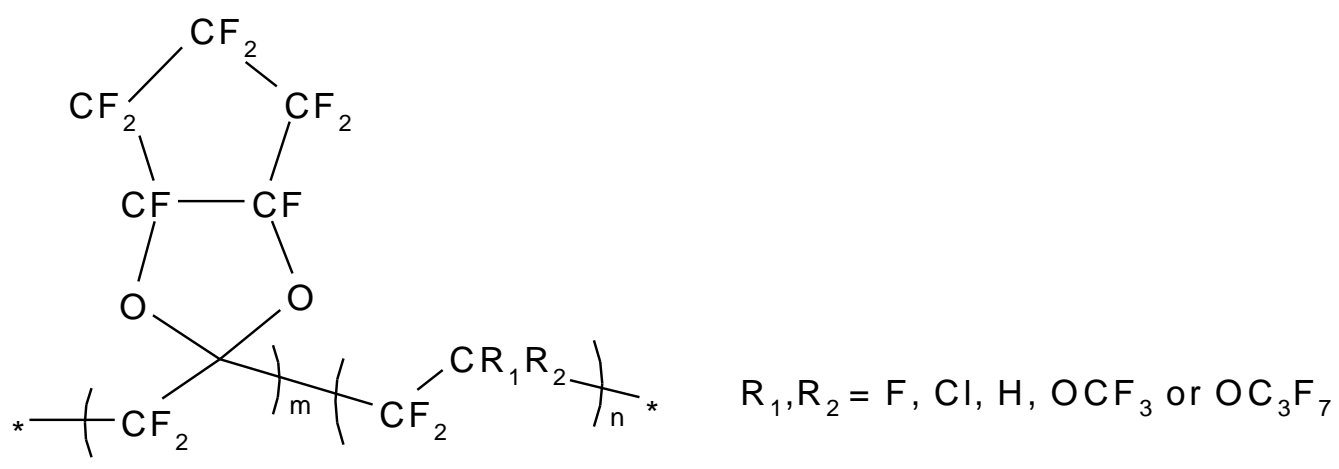




\section{FIGURE CAPTIONS}

Figure 1. Polymerization rates of perfluorodioxolane monomers versus their methylene double bond polarity.

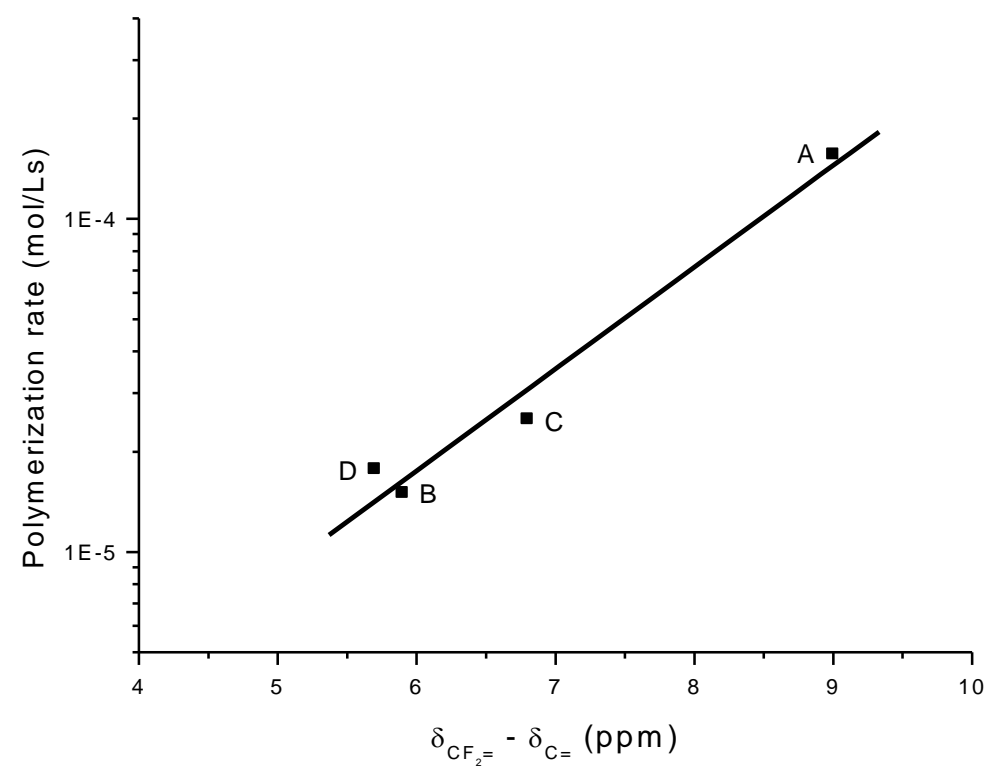


Figure 2. Monomer/polymer composition curve for the radical copolymerization of perfluoro-3methylene-2,4-dioxabicyclo[3,3,0] octane (monomer D) with CTFE (curve 1 from Kelen-Tudos and curve 2 from Fineman-Ross law).

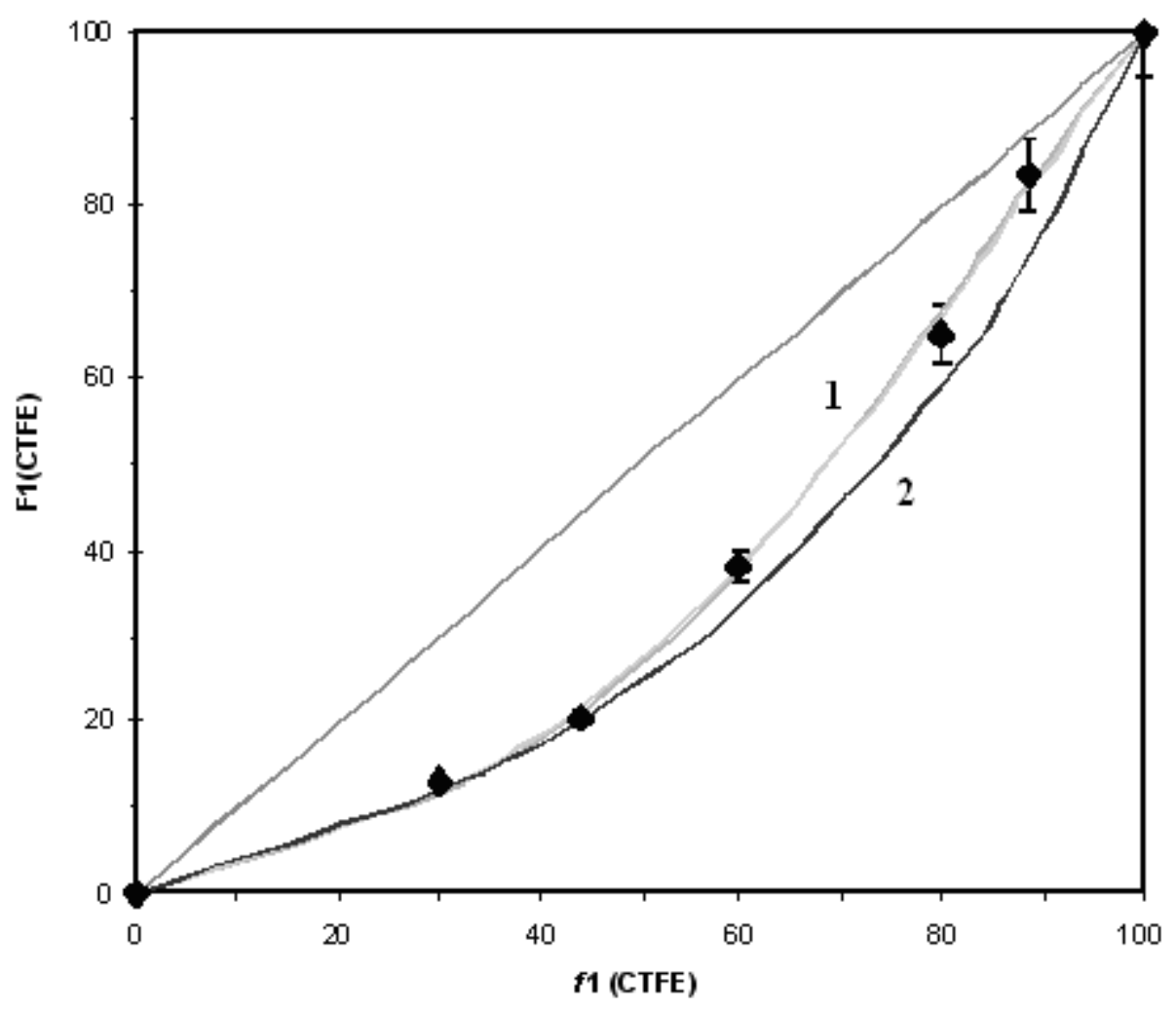


Figure 3. Composition dependence of perfluoro-3-methylene-2,4-dioxabicyclo[3,3,0] octane (monomer $\mathrm{D}$ ) on $\mathrm{T}_{\mathrm{g}}$ values of poly(CTFE-co-D) copolymer.

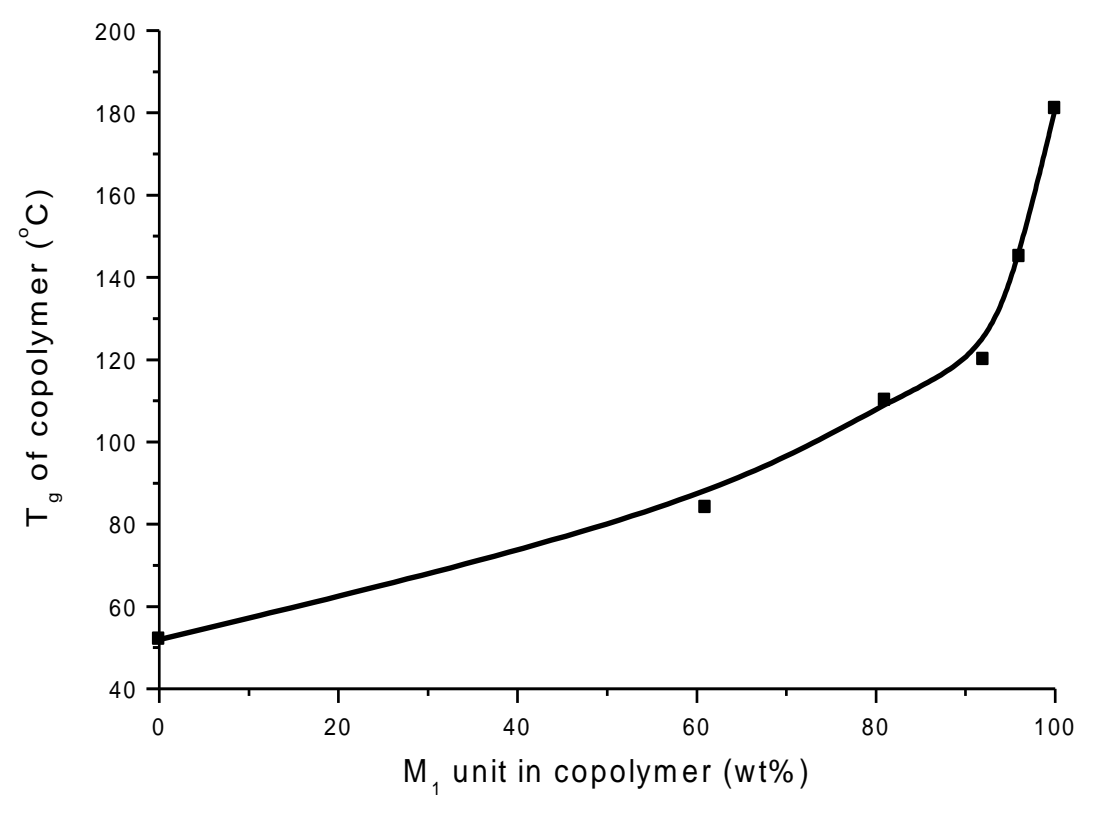


Figure 4. FTIR spectra of copolymers (run 2 and run 3 in Table 3).

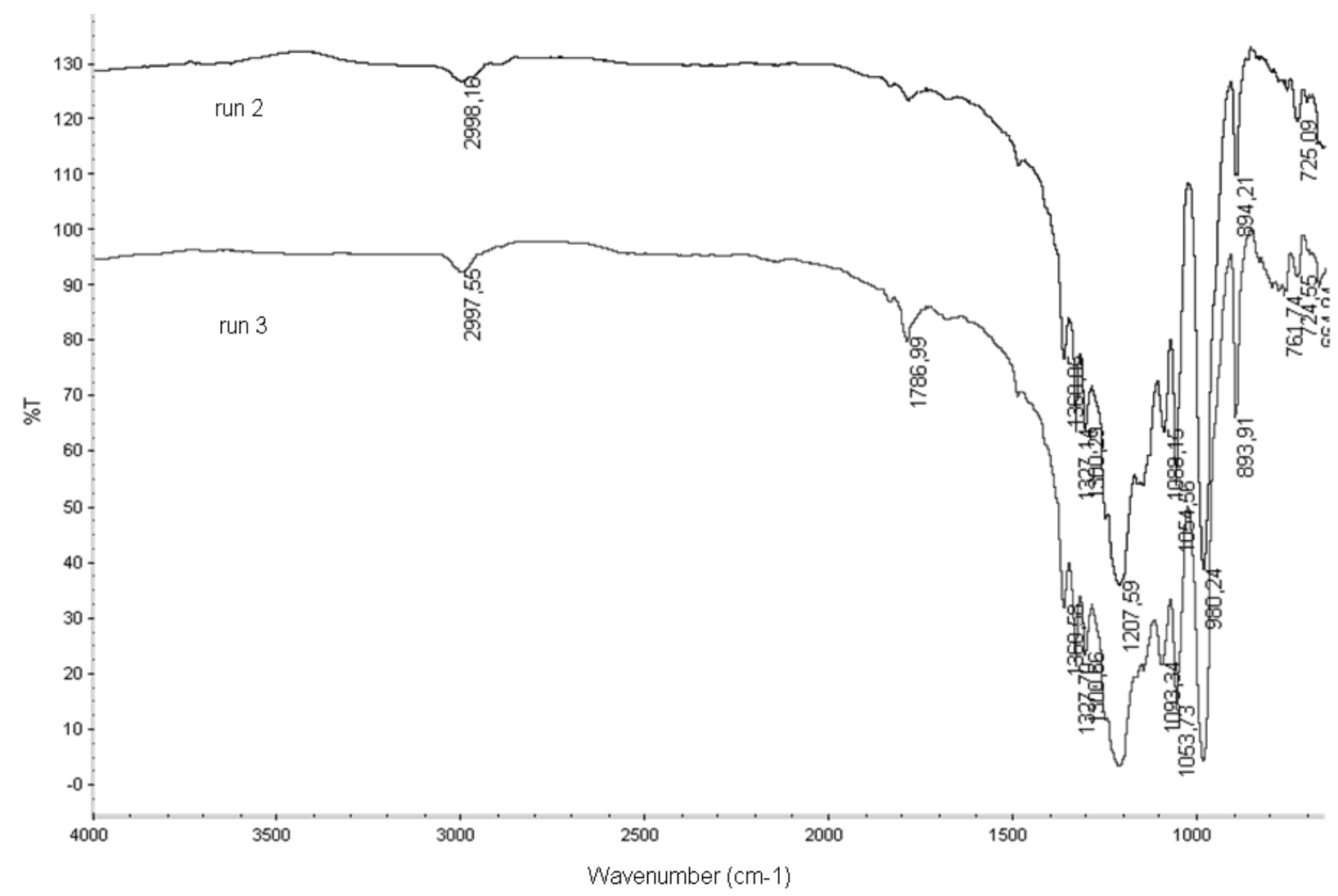


Figure 5. ${ }^{19}$ F-NMR spectrum of copolymer Run 2 in Table 3.

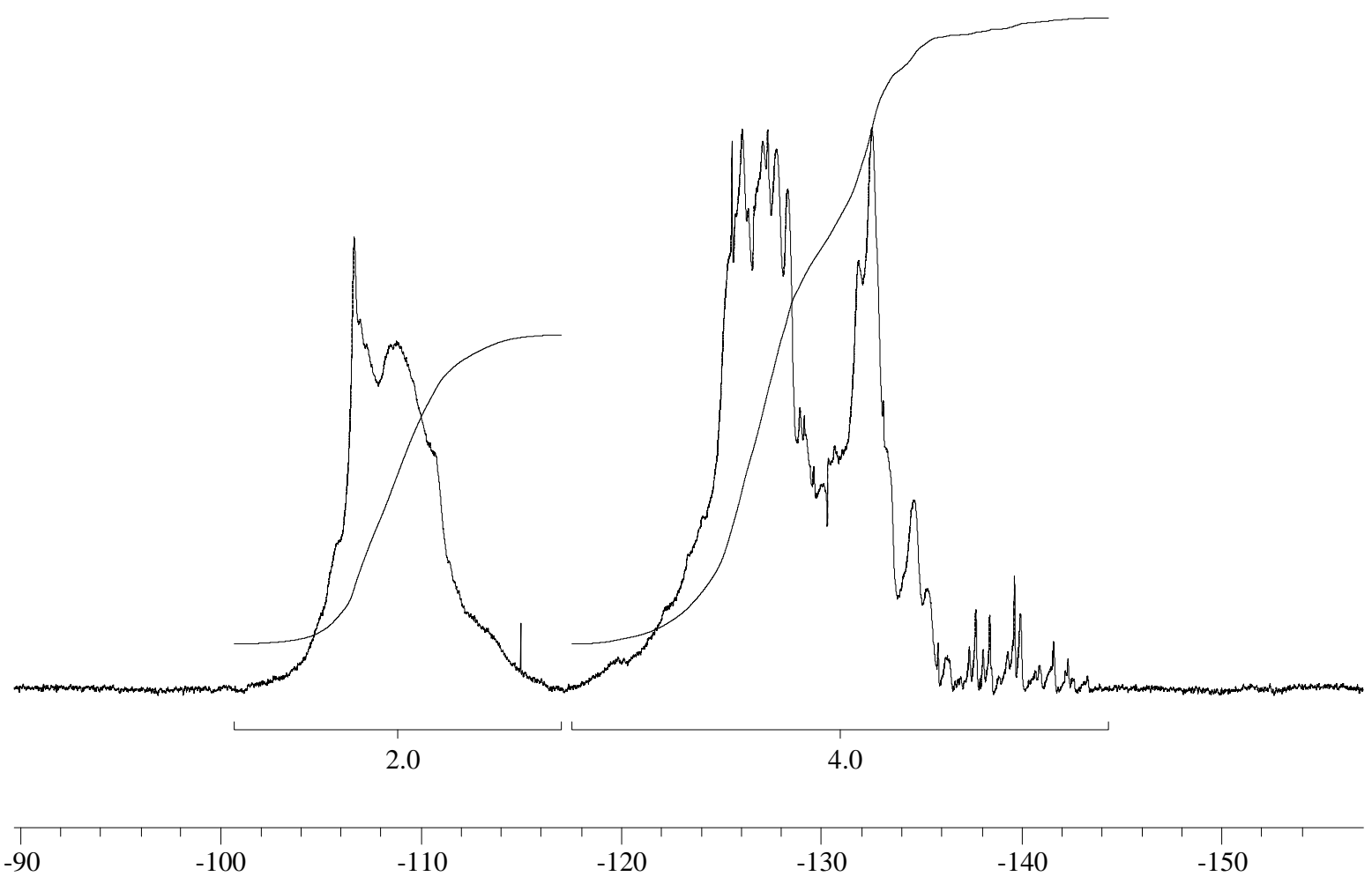


Figure 6. TGA thermogram of D/CTFE copolymer (Runs 3 in Table 3).

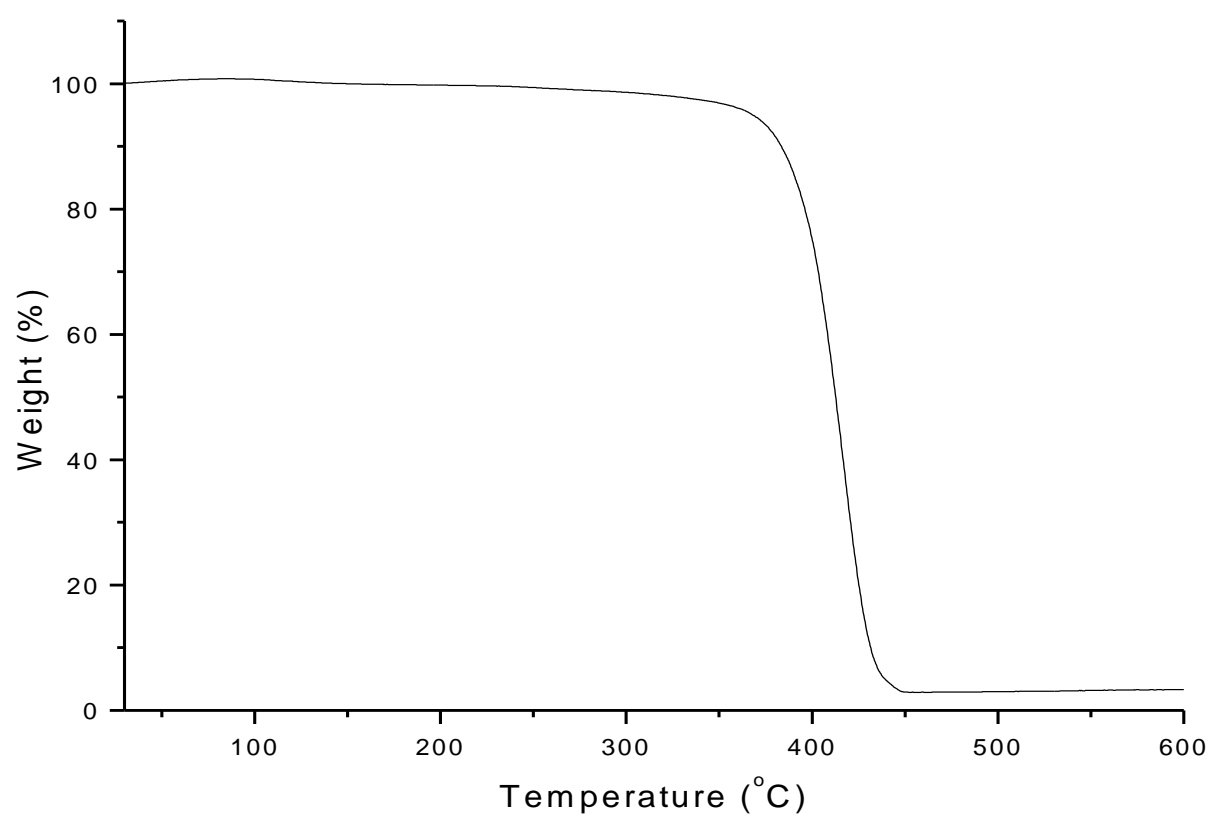


Graphical Abstract:

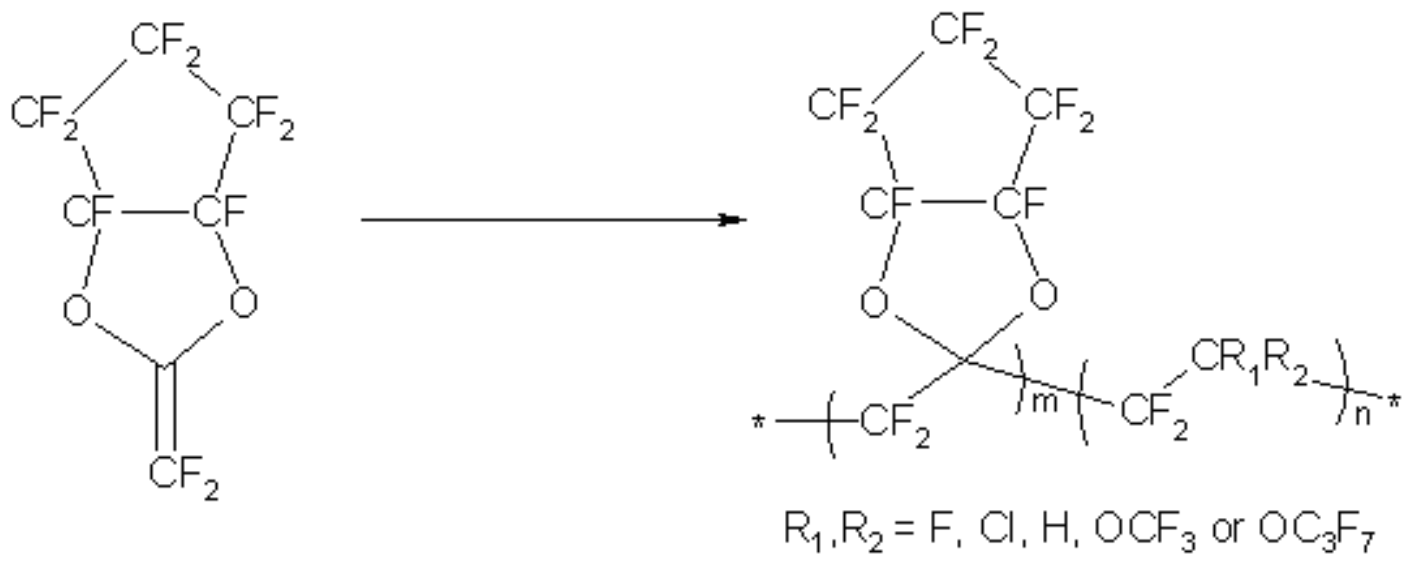

Perfluoro-3-methylene-2, 4-dioxabicyclo[3,3,0] octane was synthesized via direct fluorination of the corresponding hydrocarbon precursor by $\mathrm{F}_{2} / \mathrm{N}_{2}$. The homopolymer obtained was thermally stable with glass transition temperature $\left(\mathrm{T}_{\mathrm{g}}\right) 180 \sim 190{ }^{\circ} \mathrm{C}$. The film made from the homopolymer was transparent with refractive index 1.3290 at $633 \mathrm{~nm}$. The copolymers of the monomer were prepared with chlorotrifluoroethylene, perfluoropropyl vinyl ether, perfluoromethyl vinyl ether and vinylidene fluoride. The copolymers obtained were soluble in hexafluorobenzene and perfluoro-2-butyltetrahydrofuran with $\mathrm{T}_{\mathrm{g}} 84 \sim 145^{\circ} \mathrm{C}$. The films of the copolymers were flexible and transparent with a low refractive index (1.3350 1.3770 at $533 \mathrm{~nm})$. 